\title{
Germ cell development in equine testis tissue xenografted into mice
}

\author{
R Rathi ${ }^{1}$, A Honaramooz ${ }^{1,2}$, W Zeng ${ }^{1}$, R Turner $^{1}$ and I Dobrinski ${ }^{1}$ \\ ${ }^{1}$ Center for Animal Transgenesis and Germ Cell Research, School of Veterinary Medicine, University of Pennsylvania, \\ Kennett Square, PA 19348, USA and ${ }^{2}$ Western College of Veterinary Medicine, University of Saskatchewan, 52 \\ Campus Drive, Saskatoon, SK, Canada S7N 5B4
}

Correspondence should be addressed to Ina Dobrinski; Email: dobrinsk@vet.upenn.edu

\begin{abstract}
Grafting of testis tissue from immature animals to immunodeficient mice results in complete spermatogenesis, albeit with varying efficiency in different species. The objectives of this study were to investigate if grafting of horse testis tissue would result in spermatogenesis, and to assess the effect of exogenous gonadotropins on xenograft development. Small fragments of testis tissue from 7 colts ( 2 week to 4 years of age) were grafted under the back skin of castrated male immunodeficient mice. For 2 donor animals, half of the mice were treated with gonadotropins. Xenografts were analyzed at 4 and 8 months post-transplantation. Spermatogenic differentiation following grafting ranged from no differentiation to progression through meiosis with appearance of haploid cells. Administration of exogenous gonadotropins appeared to support post-meiotic differentiation. For more mature donor testis samples where spermatogenesis had progressed into or through meiosis, after grafting an initial loss of differentiated germ cells was observed followed by a resurgence of spermatogenesis. However, if haploid cells had been present prior to grafting, spermatogenesis did not progress beyond meiotic division. In all host mice with spermatogenic differentiation in grafts, increased weight of the seminal vesicles compared to castrated mice showed that xenografts were releasing testosterone. These results indicate that horse spermatogenesis occurs in a mouse host albeit with low efficiency. In most cases, spermatogenesis arrested at meiosis. The underlying mechanisms of this spermatogenic arrest require further investigation.
\end{abstract}

Reproduction (2006) 131 1091-1098

\section{Introduction}

Grafting of testis tissue from immature animals of different mammalian species to immunodeficient mice can result in complete spermatogenesis with production of viable spermatozoa capable of fertilization (Shinohara et al. 2002, Honaramooz et al. 2002, 2004, Schlatt et al. 2003, Snedaker et al. 2004). However, the efficiency of spermatogenesis in testis xenografts varies among donor species. While full spermatogenesis comparable to that in the donor species develops in xenografts from pigs and goats (Honaramooz et al. 2002), spermatogenic differentiation is less efficient in testis tissue from cats, monkeys, and bulls (Rathi et al. 2005, Honaramooz et al. 2004, Oatley et al. 2004, 2005, Snedaker et al. 2004). The mechanisms underlying these species differences remain to be elucidated.

Xenografting of horse testis tissue onto a mouse host has not been reported previously. If effective, testis tissue xenografting could provide an accessible in vivo model to facilitate the study of equine spermatogenesis. This model would permit, for example, replication of treatments within donors, thus reducing variability of results due to male effects while minimizing the use of large experimental animals. In addition, sperm produced in equine testis xenografts could be used to generate offspring by ICSI (Cochran et al. 1998) and thereby preserve the genetics of valuable horses even following castration or death.

The pituitary gonadotropins, follicle stimulating hormone $(\mathrm{FSH})$ and luteinizing hormone $(\mathrm{LH})$, directly affect testicular growth and development, including steroidogenesis and gametogenesis (Singh \& Handelsman 1996, Haywood et al. 2003). After xenografting into a castrated mouse, donor testis tissue development is supported by the endogenous gonadotropins of the host. Stimulation of graft Leydig cells by mouse LH leads to production of bioactive testosterone and establishment of a feedback system between the graft and the mouse pituitary (Honaramooz et al. 2002). Differences between mouse and donor species gonadotropic hormones (Bousfield et al. 1996) may lead to inefficient interaction between the murine gonadotropins and the donor testis 
tissue, thus leading to insufficient amounts of hormones interacting with the grafted donor tissue. It is possible, therefore, that supplementation of host mice with exogenous gonadotropins could enhance spermatogenesis in testicular xenografts.

The objectives of this study were to determine the efficiency of spermatogenesis in horse testis tissue grafted onto mice, and to determine if the administration of exogenous gonadotropins to the host mouse would improve spermatogenic efficiency within the horse grafts.

\section{Materials and Methods}

\section{Donor testis tissue, recipient animals and procedures for xenografting}

In experiment 1 , testes were obtained from 5 colts following castration ( 2 week old Standardbred, 5 month old Welsh pony, 10 month old Warmblood, 12 month old Quarterhorse, and 4 year old Thoroughbred). Small fragments of testis tissue fragments from each donor were grafted under the back skin of castrated male immunodeficient mice ( $n=6$ mice per donor) as previously described (Honaramooz et al. 2002). Briefly, after removal of the capsule and overt connective tissue, donor testes were cut into small fragments (about 1-2 $\mathrm{mm}$ in diameter). Pieces of donor testis tissue were fixed at the time of grafting as described below to serve as baseline reference histology for graft development. Testis fragments were kept in Dulbecco's modified Eagle's medium (Gibco Lab Inc., Grand Island, NY, USA) on ice until grafting. Recipient immunodeficient (ICR-scid or NCR-nude; Taconic, Germantown, NY, USA) male mice (6 week old) were anesthetized and castrated, and during the same surgery, eight pieces of donor testis tissue fragments were grafted under the back skin of each mouse. Animals were handled and treated in accordance with the guidelines of the University of Pennsylvania's Institutional Animal Care and Use Committee. Comparable tissue pieces were fixed at the time of grafting as a reference for graft development.

\section{Gonadotropin treatment}

In experiment 2, testis tissue from two additional colts (8 month old Shetland pony, 12 month old Thoroughbred) were grafted under the back skin of castrated immunodeficient mice ( 6 each) as described above. Three of the 6 recipient mice per donor were subcutaneously injected with $10 \mathrm{IU}$ of PMSG (Sioux Biochemical Inc., Sioux Center, IA, USA) and 10 IU of hCG (Chorulon, Intervet, DE, USA) twice weekly. The treatment was begun 14 weeks post-grafting in mice with Shetland pony grafts and continued for 20 weeks. For the mice carrying grafts from the 12 month old Thoroughbred, the treatment was begun 25 weeks post-grafting and continued for 10 weeks. The remaining untreated mice served as controls.

\section{Recovery and analysis of xenografts}

The host mice were killed by $\mathrm{CO}_{2}$ inhalation 4 or 8 months post-grafting. The grafts were recovered and fixed overnight in Bouin's solution followed by three changes of $70 \%$ ethanol before being embedded in paraffin and processed for histology.

In each histological section of each graft, all seminiferous cord/tubule cross-sections were examined. Seminiferous cords/tubules that were collapsed and did not contain distinct cell types were considered to be degenerated.

The status of testicular maturation was based on seminiferous tubule lumen formation, and spermatogenesis (most advanced germ cell type). The percentages of seminiferous tubules and degenerated tubules within a healthy graft were presented. Germ cells were identified by their morphology and location in the seminiferous cord/tubule. The most advanced germ cell type present in a seminiferous cord/tubule was assessed and the percent of cords/tubules with the most advanced germ cell type was presented.

A graft was classified as healthy if it was recovered and if it contained even a single seminiferous cord/tubule with germ cells, when assessed histologically. It was classified as degenerated if it either could not be recovered or if it contained only degenerated seminiferous tubules. Only data from healthy grafts were subsequently analyzed.

Mouse was considered the experimental unit and the data obtained from grafts from a single mouse were pooled. Seminal vesicles from all recipient mice were weighed as an indication of secretion of bioactive testosterone by the xenografts (Honaramooz et al. 2002, 2004, Schlatt et al. 2003).

\section{Statistical analysis}

The data from NCR-nude mice and ICR-scid mice were pooled since no difference in graft development or maturation was observed between the two strains. Where appropriate, a Chi-square or a Student's $t$-test was performed to compare two groups, and when comparing more than one group ANOVA was used. Data were analyzed using SigmaStat 3.0 (SPSS Inc., Chicago, IL, USA). Data were expressed as means \pm s.E.M and $P<0.05$ was considered significant.

\section{Results}

\section{Graft recovery}

Of the xenografts recovered from the 30 host mice, $65 \%$ were healthy. Healthy grafts had increased 2-4-fold in size compared to their sizes prior to grafting. Figure 1 shows the percentage of healthy grafts recovered ( 4 and 8 months post-grafting) for each of the 5 donors in experiment 1 . The highest percentage of healthy grafts 


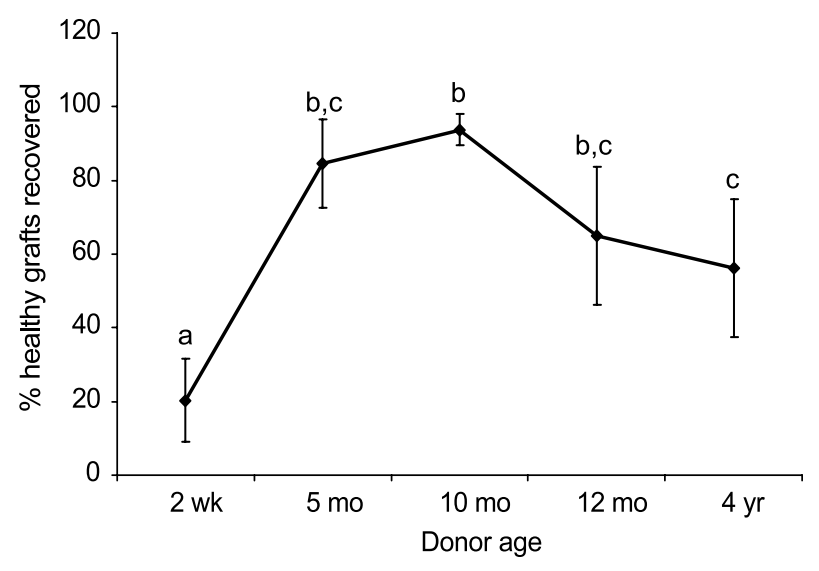

Figure 1 Percentage of healthy xenografts per donor recovered at 4 and 8 months post-grafting ( $n=6$ host mice per donor). Graft survival rate was highest in the tissue obtained from 5 and 10 month old donors and lowest in the tissue obtained from the 2 week old donor. Means with different letters $(\mathrm{a}, \mathrm{b}, \mathrm{c})$ are significantly different $(P<0.05)$.

(84.6\% and $93.8 \%$ respectively) was recovered from mice carrying tissue from the 5 and 10 month old donors ( $n=6$ mice per donor). Few healthy grafts $(20.3 \%)$ were recovered from the 6 mice with tissue from the 2 week old donor. Recovery of healthy grafts from the 12 month and 4 year old donors were intermediate $(65.0 \%$ and $56.3 \%$ respectively).

\section{Spermatogenesis and seminiferous tubule development}

At the time of grafting, the tissue from the 2 week old Standardbred horse was comprised mainly of interstitial cells with very few seminiferous cords. The most advanced germ cells within the seminiferous cords were gonocytes. Grafts harvested from the recipient mice at 4 and 8 months post-grafting showed little development. Only $37.5 \% \pm 4.8$ of the seminiferous cords developed into seminiferous tubules, while $52.0 \% \pm 2.2$ of the cords degenerated. Additionally, gonocytes/spermatogonia remained the most advanced germ cell type observed at both time points after grafting. In the grafts recovered after 8 months, organization of seminiferous tubules into lobules was more apparent, indicating some differentiation of the grafted tissue.

At the time of grafting, the tissue from the 5 month old Welsh pony consisted mostly of seminiferous cords that were grouped in clusters and arrangement in lobules was distinct. Cords contained gonocytes and/or spermatogonia as the most advanced germ cell type (Fig. 2A and $3 \mathrm{~A}$ ). By 8 months post grafting, $10.0 \% \pm 0.5$ of the seminiferous tubules contained pachytene spermatocytes as the most advanced germ cell type (Fig 2B and 3A). Over all, the healthy grafts consisted of $75.8 \% \pm 5.2$ seminiferous tubules and $4.8 \% \pm 0.8$ degenerated tubules.

Tissue from the 10 month old Warmblood horse was histologically more developed at the time of grafting.
Prior to grafting, the tissue consisted of $77.1 \%$ seminiferous tubules. Pachytene spermatocytes were the most advanced germ cell type observed in $35.0 \%$ of the tubules (Fig. 2C and 3B). At 4 months post-grafting, pachytene spermatocytes remained the most advanced germ cell type but they now were observed only in $7.1 \% \pm 3.8$, of the tubules $(n=3$ mice, Fig. 3B). This suggested that some degree of germ cell loss had occurred in the grafts over this 4 month period. However, significant development was observed in grafts recovered at 8 months. Spermatogenesis had progressed through meiosis as evidenced by the presence of elongating spermatids in $4.6 \% \pm 1.5$ of the tubules (Fig. 2D and 3B). Round spermatids were the most advanced germ cell stage in $3.2 \% \pm 0.4$ of the tubules and pachytene spermatocytes were the most advanced germ cell stage in $40.6 \% \pm 5.5$ of the tubules (Fig. 3B). In all, the recovered healthy xenografts from the 6 mice consisted of $69.8 \% \pm 6.2$ seminiferous tubules and $7.7 \% \pm 1.5$ degenerated tubules.

At the time of grafting, complete spermatogenesis, as evidenced by the presence of spermatozoa, was observed in $38.0 \%$ and $69.0 \%$ of the tubules from the 12 month old Quarter horse and the 4 year old Thoroughbred horse respectively (Fig. 2E, G and 3C, D). By 4 months post-grafting, pachytene spermatocytes were the most advanced germ cell type present in only $8.5 \% \pm 0.3$ and $6.3 \% \pm 1.1$ of the seminiferous tubules in the xenografts from the 12 month and 4 year old donors respectively (Fig. $3 \mathrm{C}$ and D). This again suggested that germ cell loss had occurred over the initial 4 month period. Some resurgence of spermatogenesis had occurred by 8 months post-grafting as evidenced by an increase in the percentage of tubules containing pachytene spermatocytes $(20.5 \% \pm 4.5$ and $17.8 \% \pm$ 3.1 respectively Fig. $2 \mathrm{~F}, \mathrm{H}$ and $3 \mathrm{C}, \mathrm{D})$. However, no post-meiotic germ cells were identified, indicating that complete spermatogenesis had not been restored. Overall, the recovered grafted tissue from the 12 month old donor consisted of $67.3 \% \pm 6.7$ seminiferous tubules while that from the 4 year old donor consisted of only $31.2 \% \pm 9.0$ seminiferous tubules, with $6.5 \% \pm 2.2$ and $46.8 \% \pm 13.9$ of the tubules degenerated respectively.

\section{Effect of gonadotropin treatment on xenograft development}

In experiment 2, prior to grafting, the most advanced germ cell types identified in testis tissue from the 8 month old pony and 12 month old TB horse donors were gonocytes and/or spermatogonia (Fig. 4A, D and 5A, B). Three of the 6 mice per donor were treated with gonadotropins for 20 weeks ( 8 month old donor) and 10 weeks (12 month old donor) respectively and grafts were harvested 8 months after grafting.

At the time of analysis, elongated spermatids were the most advanced germ cell type present in $0.7 \% \pm 0.2$ of 

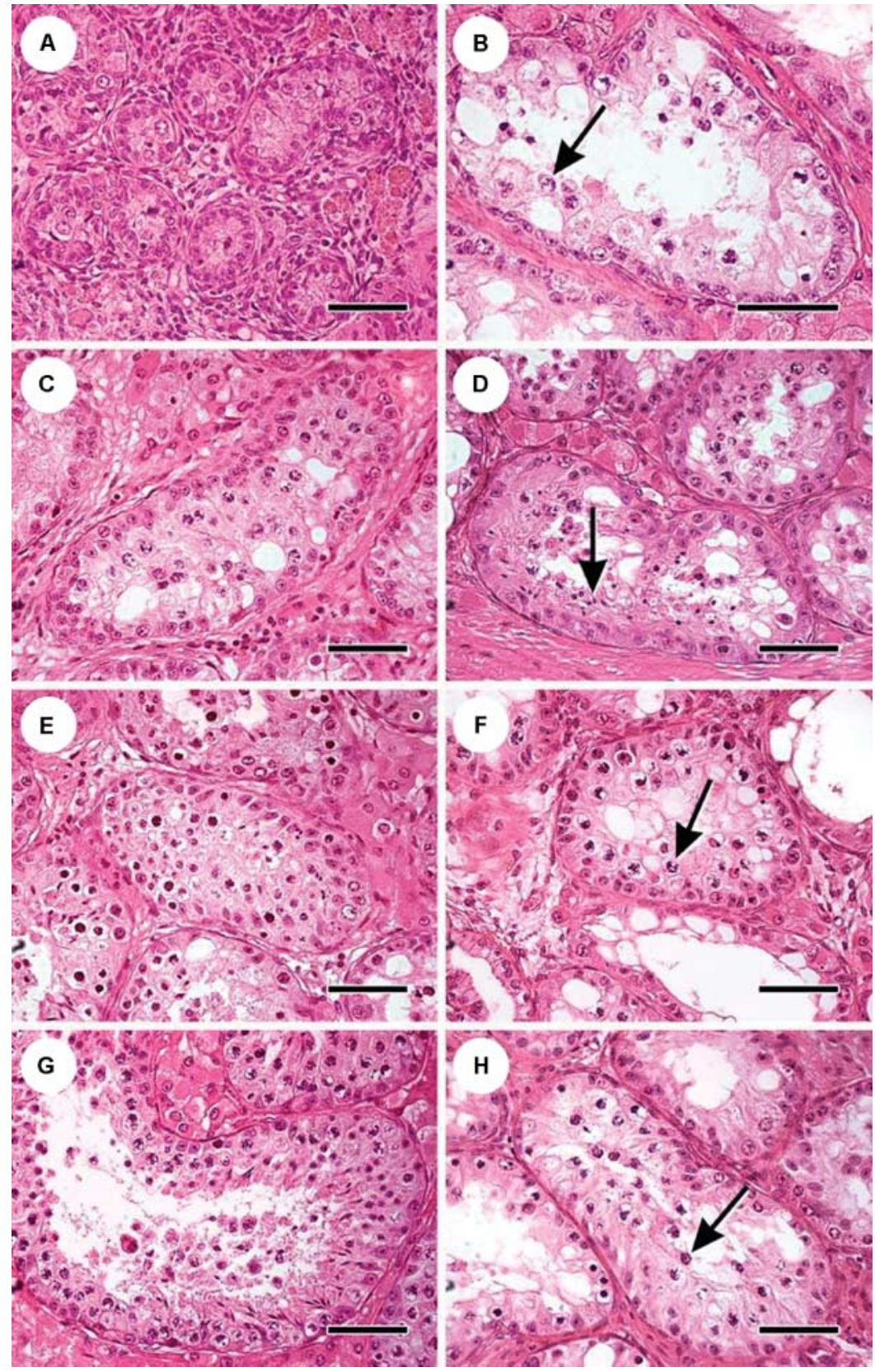

Figure 2 Histologic appearance of equine testis tissue before and after xenografting. A, C, E, G: Donor tissue prior to grafting from the 5 month old welsh pony (A) containing only gonocytes; the 10 month old warmblood (C) with pachytene spermatocytes as the most advanced germ cell type; the 12 month old Quarter horse (E), and the 4 year old Thoroughbred horse $(\mathrm{G})$, both with complete spermatogenesis. B, D, $\mathrm{F}, \mathrm{H}$ : Grafted tissue recovered 8 months post-grafting from the 5 month old welsh pony (B) with pachytene spermatocytes (arrow); the 10 month old warmblood horse (D) with elongated spermatids (arrow); the 12 month old Quarter horse (F), and the 4 year old Thoroughbred horse $(\mathrm{H})$, with pachytene spermatocytes (arrow) as the most advanced germ cell stage. Scale bars: $50 \mu \mathrm{m}$. the seminiferous tubules from the welsh pony grafts recovered from hormone treated mice (Fig. $4 \mathrm{C}$ and $5 \mathrm{~A}$ ). A higher percentage of seminiferous tubules contained round spermatids $(3 \% \pm 0.6)$ and pachytene spermatocytes $(34.6 \% \pm 5.6$, Fig. 5A). In all, $85.0 \%$ healthy xenografts were recovered from the treated host mice $(n=3)$. These grafts contained $76.0 \% \pm 6.2$ seminiferous tubules and $5.5 \% \pm 2.3$ degenerated tubules. In contrast, pachytene spermatocytes were the most advanced germ cell stage present in $20.2 \% \pm 6.1$ of the seminiferous tubules in grafts recovered from the control mice (Fig. 4B and $5 A$ ). No post-meiotic cells were observed. Seventy percent healthy xenografts were recovered from control mice, which was significantly $(P<0.05)$ less than that recovered from the treated mice. These grafts contained $71.2 \% \pm 3.2$ seminiferous tubules and $5.3 \% \pm 3.2$ degenerated tubules.

At the time of analysis, pachytene spermatocytes were the most advanced germ cell stage present within $7.6 \% \pm 3.2$ of the seminiferous tubules from the TB horse grafts recovered from hormone treated mice (Fig. 4F and 5B). Seminiferous cords were developing into seminiferous tubules. Overall, $50 \%$ healthy xenografts were recovered from the treated host mice $(n=3)$. These grafts contained $73.4 \% \pm 5.2$ seminiferous tubules and $5.5 \% \pm 1.2$ degenerated tubules. In the grafts 


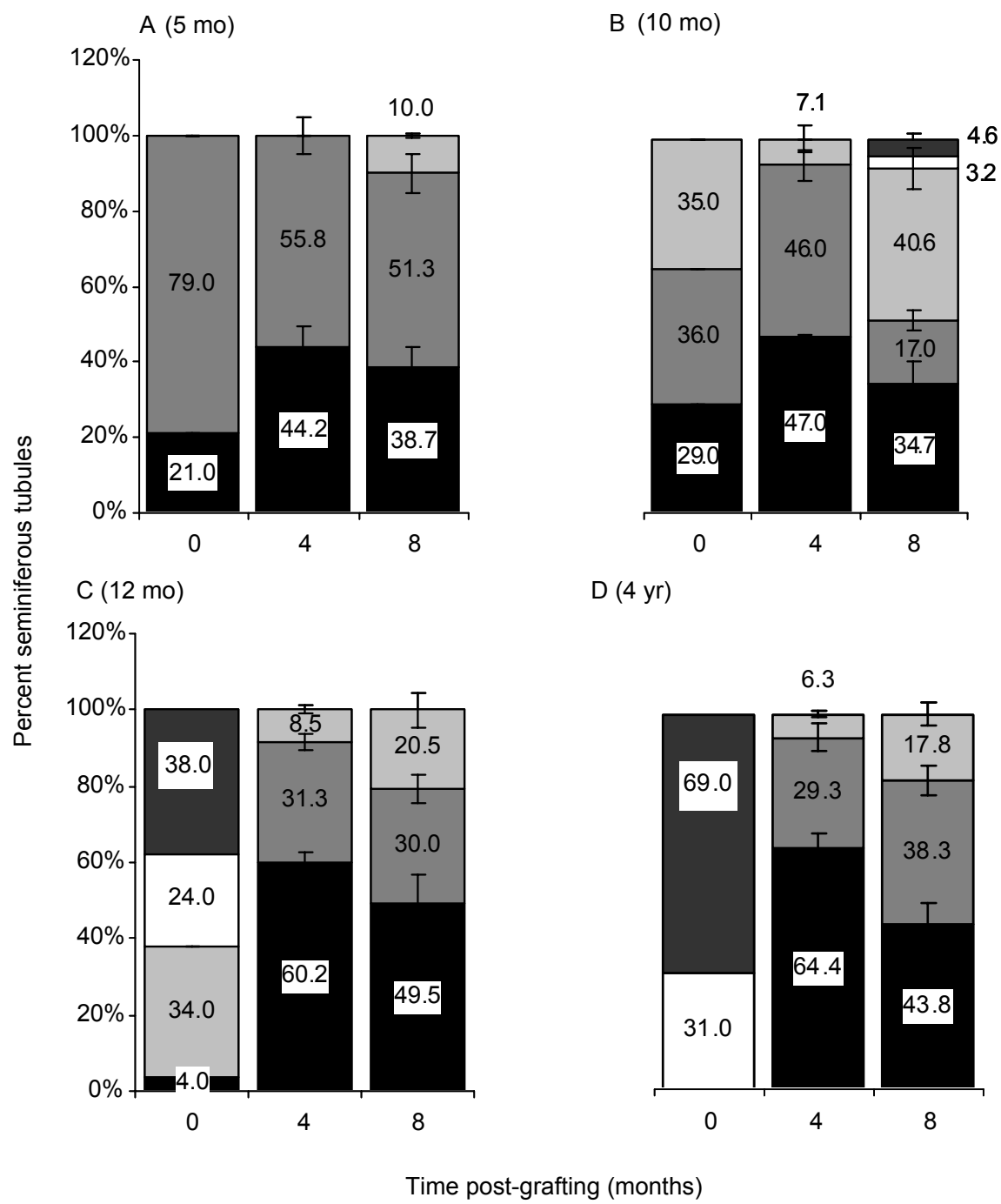

Figure 3 Seminiferous cords/tubules classified based upon the most advanced spermatogenic cell type present in each cord or tubule. The percentages of seminiferous tubules containing the indicated germ cell type as the most advanced stage is shown. (A) 5 month old donor, (B) 10 month old donor, (C) 12 month old donor and (D) 4 year old donor (D). Numbers beneath the graphs indicate the time post-grafting in months. The zero time point shows the percentages of each tubule classifaction at the time of grafting. Results are presented as mean \pm s.E.M. ( $n=6$ per group).

harvested from the control mice, a similar development of seminiferous cords into seminiferous tubules was seen. However, spermatogenesis did not proceed to meiosis as evidenced by the presence of only spermatogonia within the seminiferous tubules (Fig. 4E and 5B). Graft recovery was $50 \%$ in control mice. Compared to the treatment group these grafts contained significantly fewer seminiferous tubules $(38.6 \% \pm 7.3, P<0.05)$ and significantly more degenerated tubules $(14.1 \% \pm 3.2$, $P<0.05)$.

\section{Seminal vesicle weights}

A significant increase in seminal vesicle weights, over the castrated levels, was observed in all recipient mice carrying healthy grafts. The average seminal vesicle weight was $177 \mathrm{mg} \pm 30.8$ at 4 months post-grafting and $130.9 \mathrm{mg} \pm 27.4$ at 8 months post-grafting. In both untreated and hormone-treated mice without healthy graft development, the weights of the seminal vesicles was low (15.6 mg \pm 2.7$)$. These findings indicate that functional equine testis xenografts produce bioactive testosterone. If grafts did not develop, exogenous gonadotropin administration did not result in significant growth of the seminal vesicles.

\section{Discussion}

Ectopic grafting of testicular tissue from several mammalian species into immunodeficient mouse hosts resulted in varying degrees of donor-derived spermatogenesis. Whereas sperm production in porcine testis 


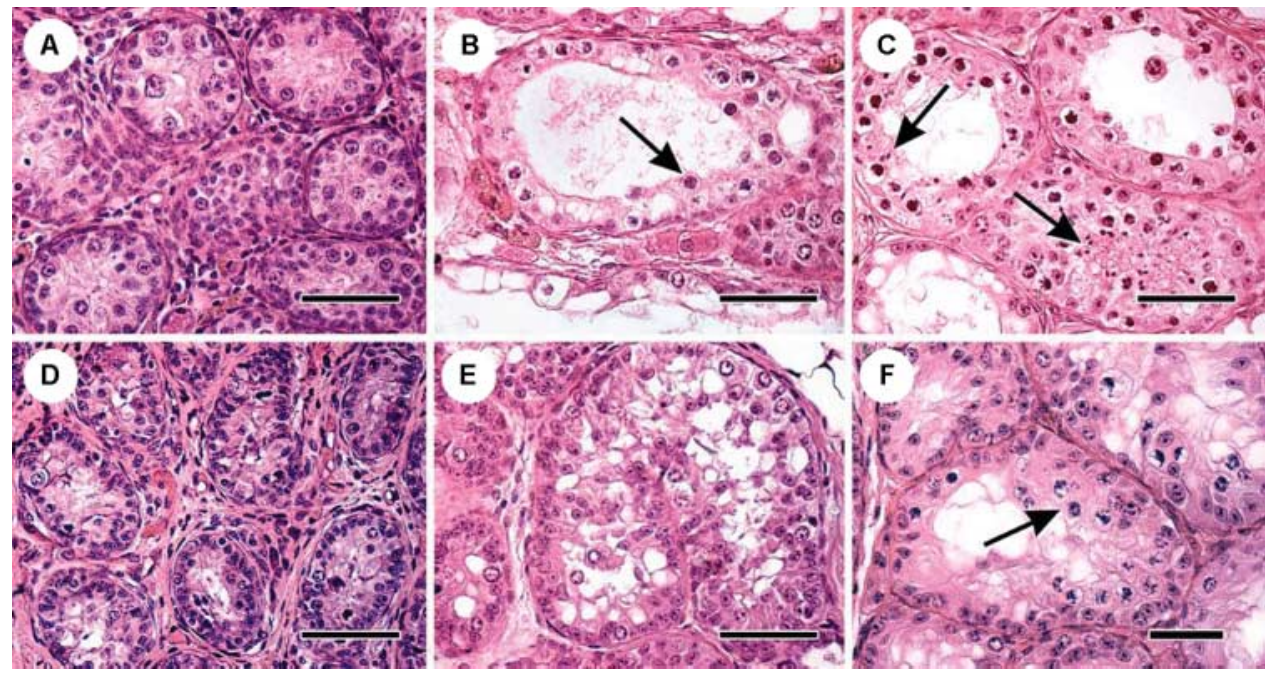

Figure 4 Histologic appearance of equine testis tissue before and after xenografting —recovered from control mice and mice treated with exogenous gonadotropins. A,B,C: Tissue from the 8 month Welsh pony prior to grafting (A), 8 months post-grafting recovered from a control mouse (B) showing pachytene spermatocytes (arrow), and recovered from a gonadotropin-treated mouse (C) showing elongated spermatids (arrows). D,E,F: Tissue from the 12 month Thoroughbred horse prior to grafting (D), 8 months post-grafting recovered from a control mouse (E), and from a gonadotropin-treated mouse $(\mathrm{F})$ showing pachytene spermatocytes (arrows). Scale bars: $50 \mu \mathrm{m}$.

xenografts can reach efficiency similar to the donor species on a per gram tissue basis (Honaramooz et al. 2002), testis tissue from other mammalian species results in inefficient spermatogenesis with elongated spermatids appearing in no more than $5-10 \%$ of the seminiferous tubules (Honaramooz et al. 2004, Snedaker et al. 2004, Oatley et al. 2004, 2005).

In the present study we showed that testis tissue from horses undergoes complete spermatogenesis in a mouse host, although at low efficiency. In our 10 month old donor testis tissue grafts, the percentage of equine tubules that progressed to contain haploid cells was comparable to that reported for cattle, cats and monkeys (Honaramooz et al. 2004, Oatley et al. 2004, 2005, Snedaker et al. 2004). Very immature tissue (from the 2 week old colt) showed no apparent development. At the other end of the spectrum, mature tissue that contained full spermatogenesis at the time of grafting first went through a degenerative phase before recovering to support only partial spermatogenesis, typically arresting at meiosis.

In equine testis tissue samples that contained meiotic or post-meiotic germ cell stages at the time of grafting (i.e. 10 month old, 12 month old and 4 year old donors), an initial degeneration of spermatogenesis over the first 4 months of the study was observed. It appears that differentiated germ cells present in the tissue at the time of grafting degenerate and that renewed germ cell differentiation is subsequently initiated from the remaining spermatogonial stem cells. Therefore, differentiated germ cells seem to be more sensitive to the hypoxic damage associated with tissue harvest and grafting than are earlier stages of germ cell development. Also, the testis tissue from sexually mature donors did not survive as xenografts as well as the tissue from peripubertal donors. The more mature donor tissue samples (12 month and 4 year) showed evidence of tissue degeneration and an inefficient resurgence in spermatogenesis compared to the peripubertal samples. These findings, and those reported previously for adult human and hamster testis tissue, suggest that mature donor tissue might not be well suited for xenografting (Schlatt et al. 2002, 2006). Degeneration of adult tissue is probably due to its reduced ability to survive periods of ischemia during grafting (Schlatt et al. 2002) compared to less mature tissue samples.

In most cases, we observed progression of spermatogenesis up to meiosis in equine testis xenografts. However, development to post-meiotic stages was inefficient. This apparent meiotic arrest in xenografts also has been reported in bovine xenografts (Rathi et al. 2005), although the underlying causes are not yet known. Though not tested in this study, an initial loss of germ cells, soon after grafting, could occur in equine testis xenografts as reported in bovine testis xenografts (Rathi et al. 2005). However, the abundance of seminiferous tubules containing spermatocytes as the most differentiated germ cell type argues against germ cell loss as the major reason for spermatogenic inefficiency in the equine xenografts.

In the current study, the seminal vesicles recovered from the host mice were larger than those found in castrated mice, but still smaller than those found in intact male mice or in castrated mice carrying murine or bovine testis xenografts (Rathi et al. 2005, Schlatt et al. 2002, 2003). This suggests that less bioactive 


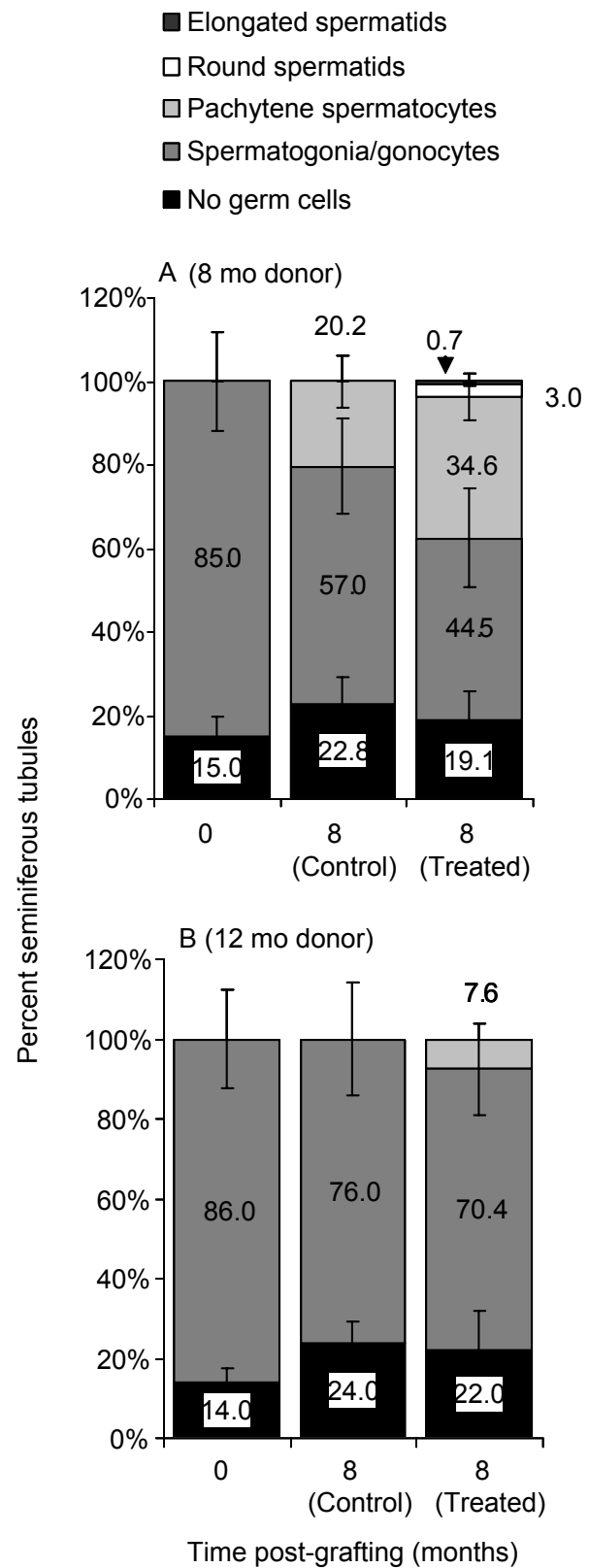

Figure 5 Relative abundance of seminiferous tubules (Yaxis) containing the indicated germ cell type as the most advanced stage recovered from gonadotropin-treated and control mice xenografted with equine testis tissue from: (A) the 8 month old donor horse; (B) the 12 month old donor horse. The $\mathrm{X}$ axis gives the time points of tissue/graft analysis. The results are presented as mean \pm S.E.M. ( $n=3$ per group).

testosterone is produced by the xenografted equine testes (Honaramooz et al. 2002, Schlatt et al. 2003) than by mice testes in situ or by xenografts from other donor species. One possible cause of the reduced testosterone production by the equine grafts is that equine Leydig cells are less responsive to murine gonadotropins. Since testosterone is produced by Leydig cells in response to $\mathrm{LH}$ and since both $\mathrm{LH}$ and $\mathrm{FSH}$ are required for spermatogenesis (Haywood et al. 2003), this led us to speculate that inadequate bioactivity of LH from the host mouse pituitary could be one cause of the inefficient testosterone production and inefficient spermatogenesis in the equine xenografts.

To test this hypothesis, we supplemented host mice with exogenous hCG for its LH-like effects and exogenous PMSG for its FSH- (and some $\mathrm{LH}$-) like effects and determined if these compounds resulted in improved maturation and subsequent sperm production in testicular xenografts. In response to stimulation by these exogenous gonadotropins, germ cell differentiation was improved compared to untreated controls with elongated spermatids observed in the grafts from the 8 month pony tissue. However, no increase in the percentage of seminiferous tubules with differentiated germ cells was observed. Interestingly, the seminal vesicles were not significantly bigger in treated recipients indicating that production of bioactive testosterone was not significantly increased. Nonetheless, these findings suggest that administration of exogenous gonadotropins had a supportive effect on testis xenograft development and germ cell differentiation.

It should be noted that increased seminal vesicle weight was observed only in mice where the xenografts showed at least development of a lumen in the seminiferous tubules. Seminiferous tubule lumen formation is testosterone dependent. In contrast no increase in seminal vesicle weight was observed in the absence of graft development. It has been reported that castrationinduced reduction in seminal vesicle size can be restored to normal by injection of testosterone (Setchell 1978). Taken together, these findings support the hypothesis that it is the testosterone produced by the graft's Leydig cells in response to endogenous or exogenous gonadotropins that leads to an increase in seminal vesicle size.

In the current study, equine testis tissue was obtained from a limited number of genetically varied horses and ponies of different ages as it became available from animals that were undergoing owner-elected castration. As such we cannot draw any firm conclusion regarding a potential effect of donor age on the developmental potential of equine testis xenografts. In spite of this limitation, we did observe some general trends in xenograft development. Tissue samples from the 2 week old donor horse failed to result in any apparent spermatogenic differentiation, raising the possibility that tissue from very young equine donors may be unsuitable for grafting. In contrast, peripubertal equine tissue containing some degree of germ cell differentiation at the time of grafting resulted in the most complete spermatogenic development. Similar to our recent report on human testis xenografts (Geens et al. 2006, Schlatt et al. 2006), tissue from sexually mature horse donors with complete spermatogenesis at the time of grafting undergoes extensive degeneration of the seminiferous epithelium following grafting with only 
limited germ cell survival. Subsequent to this degeneration stage, a partial resurgence of spermatogenesis occurs. These observed trends remain to be validated in the horse through the study of larger numbers of agematched subjects.

In summary, complete spermatogenesis occurs in a low percent of xenografts from equine testis tissue. Spermatogenesis is arrested at meiosis in the majority of tubules. Supplementation of host mice with exogenous gonadotropins slightly improves germ cell differentiation, but did not significantly affect graft development. Our data indicate that equine testis tissue can be used as a comparative model to study the underlying mechanisms that control spermatogenesis in testis xenografts. Equine testis tissue xenografts may also enhance and simplify the study of testicular physiology and pathophysiology in horses without the need for performing experiments on animals from the donor species.

\section{Acknowledgements}

We thank James Hayden, RBP, for figure preparation, and Terry Jordan for help with animal care. This study was supported by grant: USDA/CSREES/NRICGP 2003-35203-13486.

\section{References}

Bousfield GR, Butnev VY, Gotschall RR, Baker VL \& Moore WT 1996 Structural features of mammalian gonadotropins. Molecular and Cellular Endocrinology 125 3-19.

Cochran R, Meintjes M, Reggio B, Hylan D, Carter J, Pinto C, Paccamonti D \& Godke RA 1998 Live foals produced from sperminjected oocytes derived from pregnant mares. Journal of Equine Veterinary Science 18 736-740.

Geens M, de Block G, Goossens E, Frederickx V, van Steirteghem A \& Tournaye H 2006 Spermatogonia survival after grafting human testicular tissue to immunodeficient mice. Human Reproduction $\mathbf{2 1}$ 390-396.

Haywood M, Spaliviero J, Jimemez M, King NJC, Handelsman DJ \& Allan CM 2003 Sertoli and germ cell development in hypogonadal (hpg) mice expressing transgenic follicle-stimulating hormone alone or in combination with testosterone. Endocrinology 144 509-517.
Honaramooz A, Snedaker A, Boiani M, Scholer H, Dobrinski I \& Schlatt S 2002 Sperm from neonatal mammalian testes grafted in mice. Nature 418 778-781.

Honaramooz A, Li MW, Penedo MCT, Meyers S \& Dobrinski I 2004 Accelerated maturation of primate testis by xenografting into mice. Biology of Reproduction 70 1500-1503.

Oatley JM, Reeves JJ \& Mclean DJ 2004 Spermatogenesis and germ cell transgene expression in xenografted bovine testicular tissue. Biology of Reproduction 71 494-501.

Oatley JM, Reeves JJ \& Mclean DJ 2005 Establishment of spermatogenesis in neonatal bovine testicular tissue following ectopic xenografting varies with donor age. Biology of Reproduction 72 358-364.

Rathi R, Honaramooz A, Zeng W, Schlatt S \& Dobrinski I 2005 Germ cell fate and seminiferous tubule development in bovine testis xenografts. Reproduction 130 923-929.

Schlatt S, Kim SS \& Gosden R 2002 Spermatogenesis and steroidogenesis in mouse, hamster and monkey testicular tissue after cryopreservation and heterotopic grafting to castrated hosts. Reproduction 124 339-346.

Schlatt S, Honaramooz A, Boiani M, Scholer HR \& Dobrinski I 2003 Progeny from sperm obtained after ectopic grafting of neonatal mouse testes. Biology of Reproduction 68 2331-2335.

Schlatt S, Honaramooz A, Ehmcke J, Goebell PJ, Rübben H, Dhir R, Dobrinski I \& Patrizio P 2006 Limited survival of adult human testicular tissue as ectopic xenograft. Human Reproduction 21 384-389.

Setchell BP 1978 Endocrinology of the Testis, The Mammalian Testis, pp. 109-180. Ithaca: Cornell University Press.

Shinohara T, Inoue K, Ogonuki N, Kanatsu-Shinohara M, Miki H, Nakata K, Kurome M, Nagashima H, Toyokuni S, Kogishi K, Honjo T \& Ogura A 2002 Birth of offspring following transplantation of cryopreserved immature testicular pieces and in-vitro microinsemination. Human Reproduction 17 3039-3045.

Singh J \& Handelsman DJ 1996 The effects of recombinant FSH on testosterone-induced spermatogenesis in gonadotrophin-deficient (hpg) mice. Journal of Andrology 17 382-393.

Snedaker AK, Honaramooz A \& Dobrinski I 2004 A game of cat and mouse: Xenografting of testis tissue from domestic kittens results in complete cat spermatogenesis in a mouse host. Journal of Andrology 25 926-930.

Received 5 January 2006

First decision 25 January 2006

Revised manuscript received 9 February 2006

Accepted 27 February 2006 